\title{
A REMARKABLE NEW ISLAND ISOLATE IN THE ANT GENUS PROCERATIUM (HYMENOPTERA: FORMICIDAE)
}

\author{
By William L. Brown, Jr.** \\ Department of Entomology \\ Cornell University \\ Ithaca, New York 14850
}

In 1969, I collected in southern Africa and Madagascar, and then moved on for work in southern India, stopping en route for four days (29 March-I April) on Mauritius in order to sample the small but interesting endemic ant fauna known from this island in the Indian Ocean. My experience there was greatly enriched by aid and information from Mr. Leo Edgerly, retired chief forester of Mauritius, whose knowledge of the island and its plants, animals and people is probably unmatched.

On the second day of my stay, on Mr. Edgerly's advice, I climbed the small mountain known as Le Pouce ("The Thumb") in the Moka Range in the northern part of the island. This mountain, formerly collected by the Mauritian entomologists R. Mamet and J. Vinson, is described in Donisthorpe's paper (1946) on the ants of Mauritius. The Moka Range rises from a sea of sugar cane, and Le Pouce is separated from neighboring mountains in the narrow volcanic chain by deep saddles. It is an elongate massif, with tall, steeply dropping cliffs on all sides and a topside "plateau" sloping up gently eastward to a sudden sharp peak that gives the mountain its name. The plateau averages about $700 \mathrm{~m}$ in elevation; it is still largely covered with a low, gnarled native forest much invaded by guava and grassland. A mostly gentle trail hugs the cliffs and crosses the plateau.

The first day on Le Pouce was a bright, sunny Sunday, and the few well-marked trails through the pleateau scrub were invaded by bands of teenagers from the lowlands, equipped with portable radios. Accordingly, I stuck to the heavy vegetation. Ants were very scarce, and nearly all that I found were colonies of the small dark Solenop-

*This work was supported by United States National Science Foundation Grant GB-31662 and an earlier grant from the same agency; the support is gratefully acknowledged.

Manuscript received by the editor February 15, 1974 
sis mameti in rotten wood. Near the end of the day, when the sun was getting low, I was at the eastern end of the plateau where it begins to rise suddenly to the peak. Here a 2-centimeter-thick hollow rotting stick lying on the leaf litter unexpectedly yielded a nest of sluggish red ponerines, obviously Ectatommini in habitus. I got the nest alive into a plastic "live tube" and kept it for a week until it succumbed to mold. I was much excited by the find, although I assumed at the time that I had a species of Gnamptogenys belonging to the Indo-Australian "Stictoponera" group, because of the rather large size and more or less shining integument of the workers, and the distinct (though small to a hand lens) eyes. Even this would have been a remarkable range extension.

On the next day I collected in other parts of the island, including the scrubby "peat forest" on high ground in the south, then being destroyed and replanted (disastrously!) with hurricane-vulnerable exotic pines. The bag was discouraging, consisting almost entirely of introduced ant species. A rapid traverse with Mr. Edgerly of the southern Cocotte Mountain, badly stripped by a recent hurricane, turned up nothing but introduced ants.

On the first of April, though I was scheduled to leave on an eveing flight to Bombay, I tried Le Pouce again. A telephone call to Mr. J. Vinson, who had collected some of Donisthorpe's material, convinced me that the main path on the LePouce plateau should not be avoided. I arrived there early in the afternoon; the day was heavily overcast, threatening rain on the peaks, and it took me about an hour to walk up to the plateau. Whereas the sunny Sunday in the scrub shade had yielded almost no ants foraging, I now found foragers on foliage and on the hard-packed earth of the trail every few meters of the way.

These were mostly Camponotus aurosus and Pristomyrmex spp. (=Dodous), native Mauritian species. Before long, on the trunk of a small tree by the path, I found a sparse trail of bright red ants climbing the bark. Closer examination revealed these to be predominantly the ectatommine I had collected on the previous Sunday, but interspersed with these were workers of Pristomyrmex bispinosus (Brown, 197 I) which, with their gasters carried partly curled under, looked remarkably like the ectatommines. It is hard to avoid the impression that some kind of mimicry involves these two species in this habitat. The ectatommines ascending the trunk nearly all carried in their mandibles tiny whitish spherical objects that proved eventually to be arthropod eggs - probably spider eggs. 
I climbed the tree, which was only about 5 meters high, and soon found the nest about 3 meters up. Where two of the gnarled branches crossed, a thick pad of lichens surrounded the place where they touched. Forcing the branches apart, I found a rotted-out pocket, evidently caused by their rubbing together in high winds. The cavity extended downward several centimeters into one of the branches, and it was full of the ectatommine ants with brood and many of the round white arthropod eggs; I estimate that I removed or saw at least 200 workers, and there may have been more. The nest was very inconveniently placed, and the branch was too thick to break or cut with the small knife I had along, so I had to be satisfied with what I could extract by means of a twig wetted with alcohol, and with my fingers and forceps.

A few minutes later along the trail, I found the entrance to another nest in a small tree, also about $3 \mathrm{~m}$ above ground, and like the first one of that day, also in a rot hole covered with lichens. I took a few workers from near the entrance, and later found two foraging workers on the hard-packed earth of the trail. Further observations were made impossible by a sudden torrential rain, and it was only with great difficulty that I got back down off the mountain, partially dried out my clothes, and reached the airport in time for the flight to India.

My hosts in Calicut, Drs. A. Benedict Soans and Joyce Soans, gave me access to a stereomicroscope, and I quickly learned that the ectatommines I had were not Gnamptogenys, but Proceratium! I offer a formal description of the new Proceratium species, followed by a discussion of its relationships and its evolutionary and zoogeographic significance.

\section{Proceratium avium new species}

Figs. I, 2

Holotype worker: TL 4.8, HL 0.96, HW 0.94 (CI 98), ML 0.32, scape L 0.93 , greatest diameter of eye 0.09 , WL I.43, L petiole in side view $0.60, \mathrm{~L}$ petiolar node as seen from above 0.47 , $\mathrm{W}$ petiolar node $0.47, \mathrm{~L}$ hind tibia $0.97, \mathrm{~L}$ hind metatarsus $0.8 \mathrm{I} \mathrm{mm}$. For head length (HL), measurement is taken from the anterior lateral corners of the head (clypeus); head width (HW) excludes the eyes, and is taken just behind them. The petiolar node length excludes the brief anterior peduncle and is taken from the approximate base of the anterior nodal slope. The length of the gaster is 
taken in side view from the dorsal side of the juncture with the postpetiole straight to the most posterior part of the curve of the second (downcurved) gastric segment (true abdominal segment IV).

Paratype workers (I9 measured from 3 colonies at the type locality) : TL 4.7-5.0, HL 0.92-0.98, HW 0.9I-0.98 (CI 96-IOI), ML $0.3 \mathrm{I}-0.34$, scape L $0.90-0.99$, greatest diameter of eye close to 0.09 , WL I.38-1.49, L petiole in side view 0.59-0.6I, L petiolar node 0.42-0.47, W petiolar node $0.4 \mathrm{I}-0.47, \mathrm{~L}$ hind tibia 0.96-I.02, L hind metatarsus $0.80-0.87 \mathrm{~mm}$.

Composite description: Form of head and body more or less as shown in Figs. I and 2. Variation occurs in the following traits: Posterior border of head in full-face view varying from transverse, nearly straight (holotype) to broadly rounded with or without a narrow flattened or even feebly concave median portion, as in Fig. 2. Nuchal carina (on cervical face of head) continuing as a ventrolateral margin halfway down each side of head. Sides of head varying from approximately straight and parallel (Fig. 2) to gently convex and slightly converging anteriad. Eyes each composed of a single clear, convex facet. Median lobe of clypeus with sides feebly sinuous, as in Fig. 2, or merely weakly convex. Mandibles with 4 strong teeth, but one of these is sometimes double; in addition a small offset tooth is sometimes developed at the basal angle, normally hidden when closure is complete. The inner margin of the peduncle of the mandible has a low, suboblong, sinuous or even bidentate ridge or lamella, visible only when the mandible is open. The scapes vary in length and slightly in apical thickness, so that when laid straight back they surpass the posterior border of the head by amounts ranging from less than half their apical thickness to more than their apical thickness.

Labral shield bilobate, the lobes separated by a broad V-shaped notch; also, lateral to each lobe is a small thumb-shaped lobe or knob extending dorsomesally (flexad) of the plane of the shield from its basal ridge. Maxillary palpi 4-segmented, the basal segment short and cylindrical, the second segment flat and attached to the basal segment at nearly a right angle by a peduncle that arises from the side of II; III and IV are short elliptical segments extending in line from II. This is the characteristic form of maxillary palpi in Proceratium. Labial palpi 3-segmented.

Trunk convex from side to side, and from front to rear in side view, but the portion of the outline from mesonotum to propodeal declivity may be straight or may be interrupted by a feeble dip or saddle in the region of the obsolete metanotal groove. The propodeal 
angles may be smoothly rounded, as in Fig. 2, or may bear very low, obtuse corners that also render the sides of the declivity vaguely submarginate (30 March colony) as opposed to the rounded sides of the declivity in the I April series (Fig. 2), taken less than half a kilometer away. Seen from above, trunk broadly rounded in front, sutureless, tapering gently caudad, with a feeble suggestion of constriction behind mesonotum.

Petiole briefly pedunculate in front, the peduncle with strong anterolateral cornuae, the node varying from loaf-shaped with relatively steep, rounded anterior face (Fig. 2) and rounded sides to a lower version with more gradually sloping anterior face and sides less bulging. Postpetiolar (first gastric) segment varying in dorsoventral depth, especially near the posterior quarter or third of its length, and the individuals with deeper postpetiole tend to have the tergum of this sgment more swollen (or humped as seen in side view) than in the paratype depicted in Fig. 2.

Integument overall smooth and decidedly shining, but head, trunk, node and postpetiolar (first gastric) segment thickly sown with circular, centrally-tuberculate and piligerous foveae or coarse punctures. These foveae tend to be larger and more densely arranged, even subcontiguous in places (e.g., in the region behind the eyes), in the 30 March colony as compared with the series of I April, but the latter series vary greatly in this respect, even within samples from the same nest. The least strongly punctured individuals have the dorsa of trunk, node and postpetiole almost completely smooth and shining, the punctures here small and sparse. Antennae and legs much more finely and densely punctate, becoming more opaque apicad. Median clypeal lobe finely punctate-rugulose in a longitudinal direction; mandibles striate-punctate, but shining and coarsely punctate toward apicolateral margins. Second gastric (IV true abdominal) segment smooth, shining, with sparse piligerous punctulae. Gastric apex finely and densely punctulate, subopaque.

Pilosity abundant, moderate and uneven in length, of fine, subdecumbent to suberect tapered hairs, a little longer but much less abundant than usual in Proceratium, grading into a much shorter, appressed to decumbent pubescence-like covering as one moves apicad on antennae, legs and toward gastric apex; also a fine, appressed, medially-directed pubescence in the space between eyes and frontal carinae.

Color (of fully mature individuals) rich bright ferruginous red, legs and scapes often lighter and more yellowish; region immediately 


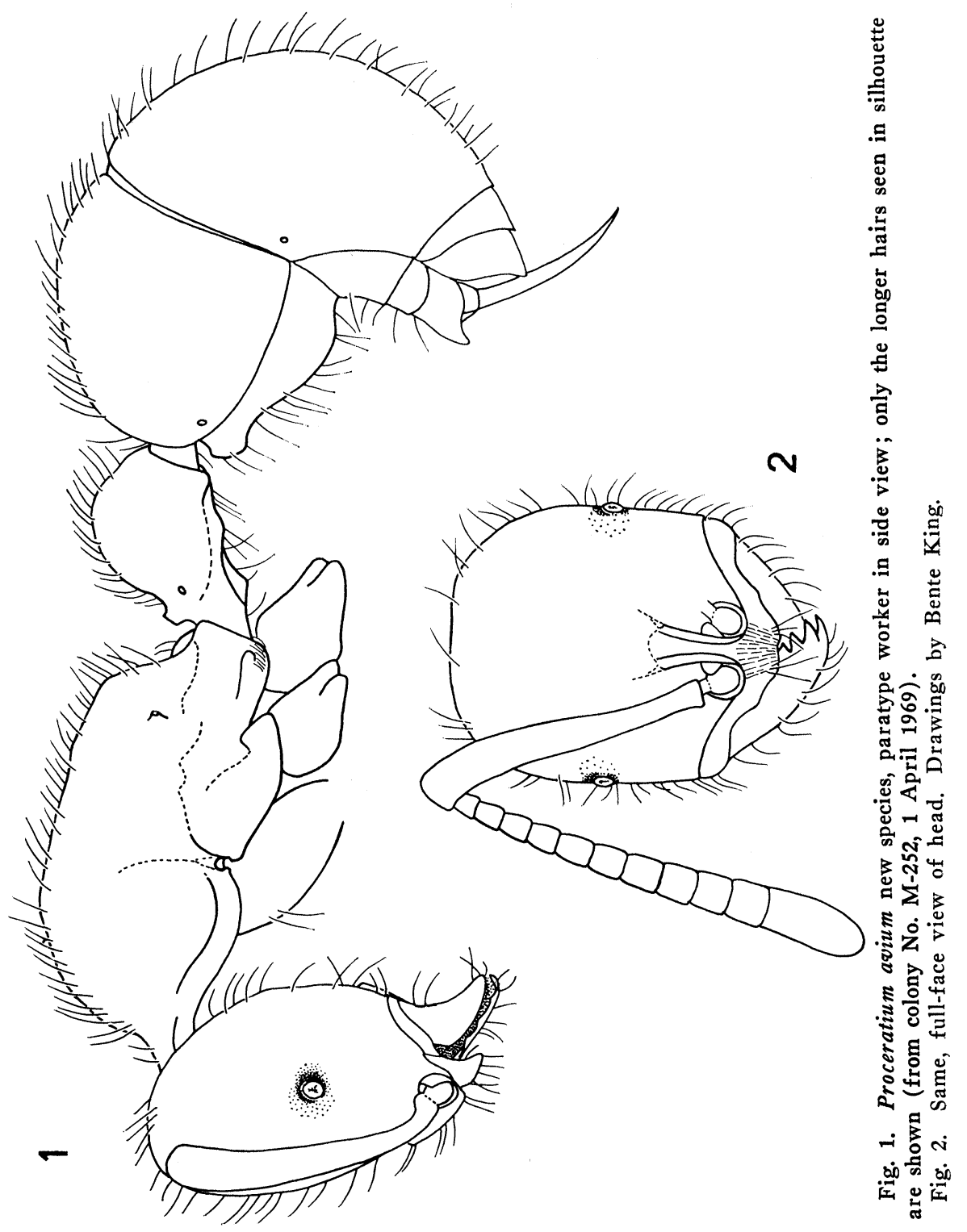


around eyes often with darker pigment. Some specimens, presumably nearer to being callow, are lighter, more yellowish-ferruginous in general color.

Malpighian tubules numbered 6 each in 4 live workers dissected, and 4 in a fifth worker, the last probably representing a mutilated specimen (dissected under less than ideal conditions). Not cryptonephric. The count of 6 agrees with a worker of $P$. goliath dissected in Costa Rica.

Queen, subergatoid (from 30 March colony): TL 5.I, HL 0.90, HW 0.92 (CI IO2), ML 0.34 (mandibles slightly opened), scape L 0.83 , greatest diameter of eye $0.14, W L$ I.38, petiole L (from above) 0.57 , petiole $\mathrm{W} .0 .58$, L hind tibia 0.87 , L hind metatarsus $0.7 \mathrm{I} \mathrm{mm}$. Head as in worker, of the shape with transverse, only feebly convex posterior border in full-face view; sides converging slightly from behind eyes toward mandibles, and bulging again slightly at lateral ends of clypeus. Mandibles with 5 moderately strong teeth and a small offset basal tooth. Ocelli small but distinct; compound eyes nearly circular in outline, moderately convex, with an estimated 70 distinct ommatidia, relatively smaller than usual in Proceratium queens. Scapes just barely overreaching posterior border of head when laid straight back.

Trunk somewhat reduced, but the usual sclerites of the pterothorax separated, except that the elements of the mesonotum are all indistinguishably fused into one gently convex continuous shield; metanotum distinct but narrow, forming the usual acute median process, but in short compressed form. Propodeum with slightly raised, but bluntly rounded angles and slightly concave, submargined declivity. Wing stumps present and blackened, but small.

Petiole shorter, broader and a little higher than in worker, the node rounded above and with a rather steep anterior face. Gaster much deeper and broader than in worker, extraordinarily voluminous, but undercurved as in worker. Sting present, stout, protrusible.

Sculpture, color and pilosity much as in the worker over head, trunk and petiole, but the punctures here shallower, less distinct and sparser than in even the more weakly foveate workers; mesonotum and node with obsolescent foveae, almost completely smooth, shining. Gaster smooth and shining, without coarse punctures, but very finely and densely punctulate, with associated dense, short, appressed pubescence and a few short, delicate decumbent to erect hairs, mainly at the posterior borders of the first segment and on the undersurfaces, and becoming abundant near the gastric apex. Due to the great bulk 
of the gaster, the fusion of the mesonotal sclerites, and the small eyes, I doubt if this queen ever had flight-functional wings.

Male (from 30 March colony): TL 4.7, HL 0.76, HW (including eyes) $0.98, \mathrm{ML} 0.29$, scape $\mathrm{L} 0.64$, greatest diameter of compound eye $0.40, \mathrm{WL}$ I.55, $\mathrm{L}$ petiole $0.55, \mathrm{~W}$ petiole $0.35, \mathrm{~L}$ hind tibia $0.93, \mathrm{~L}$ hind metatarsus 0.80 , forewing $4.0 \mathrm{~mm}$.

Head with high-domed vertex set with 3 large, clear ocelli; compound eyes large and strongly bulging, with convex inner margins as seen in full-face view of head. Median lobe of clypeus projecting, broadly truncate. Frontal carinae parallel, low but sharp, vertically raised. Mandibles triangular, each ending in a stout curved apical tooth, masticatory borders curved and cultrate. Scapes overreaching posterior border of vertex. Palpi segmented, as far as can be seen in the undissected specimen, as in worker.

Alitrunk with well-developed flight sclerites and wings; notauli lacking; scutellum semiglobose, protruding. Metanotum with the usual stout, acute median tooth. Propodeal dorsum short, convex, rounding obtusely into the declivity, which is indistinctly marginate on the sides.

Petiole long and very low, with the highest part of the gently convex node near midlength, but the greatest width at about the posterior third. Postpetiole anteriorly wider than petiole, and widening still more posteriad, but not quite as wide as the succeeding segment, which is vaulted ventrad, but not as strongly as in worker and queen.

Genitalia largely retracted (not dissected), but it can be seen that the parameres have thin, broadly rounded apices that are bent mesad toward each other.

Legs long and slender, with the usual single pectinate spur on each middle and hind tibial apex, and the tarsal claw slender and simple.

Wings of basic Proceratium pattern, with Rsf2-3 completely lacking in the forewing; $\mathrm{m}$-cu also gone; the enlarged "cubital" cell receives only one free vein distally ( $\left.\mathrm{Rsf}_{5}\right)$, because the apical free abscissa of $M$ is gone. In the hind wing, the large cell receives a short remnant of Rs and the longer free apical abscissae of $M$ and $\mathrm{CuA}$; IA is missing beyond cu-a. Wings hyaline, with light brown veins. (In the newly-discovered males of the related P. stictumfrom Brookvale, Queensland, and P. goliath-from Zent, Costa Rica, the venation pattern is similar to that of avium, but darker in goliath, still paler in stictum; $\mathrm{m}$-cu is preserved in stictum, but in the hindwings of both, the free abscissa of Rs is reduced to obsolescence.) 
Sculpture shining, with foveae much as in the worker, but also with rugulae and more opaque around the eyes, posterior scutellum, dorsum and sides of propodeum, metanotum and sides of petiole. Pilosity fine, rather short, moderately abundant, decumbent to suberect, generally distributed over body, scapes and legs. Color light yellowish-brown, gaster more brownish; vertex infuscated near ocelli and in back of compound eyes.

Holotype (from unnumbered colony, I April 1969) and paratypes (colonies ICA-69, 30 March 1969; M-252 and an unnumbered colony, plus strays, I April 1969) taken from Le Pouce (mountain), Mauritius, in native forest between 700 and 800 meters elevation on the plateau just below the peak (W. L. Brown, Jr.). Holotype and paratypes deposited in Museum of Comparative Zoology, Harvard University, Cambridge, Massachusetts, U.S.A. Paratypes in Cornell University Collection, British Museum (Natural History), Australian National Insect Collection, Canberra, Australia, and elsewhere.

$P$. avium belongs to the stictum group of Proceratium, containing two other species. P. stictum (Brown, $1958 ; 366$ ) has been known only from a single worker from North Queensland. (Now I have seen males apparently belonging to stictum, taken at light by E. S. Ross and D. Q. Cavagnaro at Brookvale, Queensland; and R. W. Taylor showed me a series that I was only able to examine hurriedly, but which looked to me like stictum, from his collections made in North Borneo.) The second species of the stictum group is $P$. goliath (Kempf and Brown, I968:94 ff.) from Costa Rica. P. avium is distinct from both of these species in its much shinier and coarser sculpture and in details of the shape of the trunk, particularly its completely unarmed propodeum, in its longer antennae, and in its less strongly undercurved gaster. $P$. avium is also much larger than $P$. stictum, but smaller than $P$. goliath, and its eyes are relatively larger than in either of these species. In fact, $P$. avium might well go into a group of its own, but the structure of the clypeus, mandibles, and petiole are so much like those of $P$. stictum and $P$. goliath that the relationship of these three species is obvious.

The characters they share are also primitive for the genus Proceratium, and this with the widely discontinuous known distribution of the group suggests that the stictum group represents the relicts of an early dispersal wave of a primitive Proceratium stock that spread widely over the earth and was overtaken (except on Mauritius) by later waves of more advanced Proceratium groups. Possibly wide- 
spread extinction of stictum-group stocks ensued; although it is not easy to visualize significant competition among such rarely-collected species, I should point out that the adaptive zone (predation of spider eggs) is a limited one. Furthermore, advanced methods of collecting, at least in North America, have proven that some advanced Proceratium species are common in suitable microhabitats. These microhabitats are, so far as we can tell, all cryptic ones - above all, in large masses of well-rotted wood. This may, of course, be an artifact of biased collecting methods, but I doubt it. On the northern fringes of the range of Proceratium - for example, in the environs of Boston $-P$. silaceum and $P$. pergandei are taken occasionally, but always under rocks in the soil. Farther south in the U.S., almost all collections are made deep in rotten wood or in humus and litter near rotten wood. The type series of $P$. goliath came from a rotten log in wet tropical forest.

The microhabitat of $P$. avium, to judge from the limited observations I have made, differs strikingly from that of other Proceratium. Certainly, the nest site is different. The first nest of $P$. avium taken on Mauritius came, it is true, from a hollow rotting stick lying on the forest floor. This may be a common kind of site for the species, yet very many such branchlets were examined on the day of collection without success, and it is possible that the branchlet had fallen recently from a tree above. In any case, I have never seen any of the eight other Proceratium species collected alive by myself in various countries nesting in such a large cavity in such an exposed site as was the colony in this stick. The other two $P$. avium nests seen were of course arboreal, with the foraging trails openly exposed for some meters over open soil and tree trunk. The ground and arboreal nesting sites for ants in wet tropical montane forest are rather academically distinguished in any case, but it seems to me that the exposure of the nests and foraging trails of $P$. avium is what is significant here. If other species of Proceratium forage so openly day or night, it has not been noted as far as I know, and indications are against it.

Of greatest interest is the contrast in habitus, especially that part owing to sculpture and pilosity, between $P$. avium and its congeners. In $P$. avium, the looser, coarser, more shining integument and its fairly long open pilosity may be compared with the finely rugulosepunctate or reticulopunctulate sculpture and very short, fine, more or less dense pilosity of the other Proceratium species. There is every reason to believe that these fine, crowded punctures and their associated hairs are a specialized evolutionary development (pushed further 
in Discothyrea) stemming from a condition in which the integument was more coarsely sculptured, with larger foveae, each fovea bearing a hair on a central tubercle. The Old World (Indo-Melanesian) Gnamptogenys stocks include species (e.g., G. menadensis) that meet these specifications and are known to be epigaeic, even arboreal, foragers (personal observations), but Gnamptogenys has reduced palpal segmentation and other characters that make it more likely a convergent than an ancestral stock to Proceratium.

I believe that Acanthoponera is nearer to the ancestral line of Proceratium because of the higher basic palpal segment number and the traces in some Proceratium species of a median carina on the frontal area and vertex of the head, characters of Acanthoponera (Brown, 1958:188). But the main question we are led to consider is: Has $P$. avium preserved some version of the archetypal Proceratium sculpture-pilosity pattern, or is its present condition a secondary reversion from the fine-scale pattern characteristic of other Proceratium around the world?

Possibly we shall never have a clearly definitive answer to this question, but we do have one clue pointing toward the reversion hypothesis. This clue is the rather unusual eyes of $P$. avium-a rather large, glassy-looking orb on each side, backed by a perceptible amount of dark pigment, and relatively larger than the characteristically single-facetted "compound" eyes of other Proceratium species. I think we have to suppose that the ancestors of $P$. avium, and also of all other Proceratium, had already specialized for a cryptic existence to the point where minute single-facetted eyes, probably barely enough to sense the difference between light and dark, served adequately the lifeways of these animals. My guess is that such lifeways also had forced selection for the fine sculpture-pilosity pattern of Proceratium in the ancestral lineage of this genus. If my reasoning is correct, then $P$. avium is an interesting example of a "characterreleased" species on a remote oceanic island with a depauperate endemic ant fauna.

The known endemic ant fauna of Mauritius numbers only about 7 species, if we take Donisthorpe's (1946, 1949) count as a base and deduct obviously introduced species, including synonyms, and add my collections. The endemics now appear to be restricted to the small areas of upland native forest; the cane fields and other culture areas are saturated with introduced ant species. In a sense, then, the mountain forests represent the "real" island(s) of Mauritius as far as the endemics are concerned. 
Among the ants of the present endemic fauna, it is difficult to pick out any that might be serious competitors of Proceratium avium. Our assumption here, of course, is that $P$. avium subsists primarily on arthropod eggs, probably mainly the eggs of spiders. (But the assumption rests on only a few observations, which need augmentation.). Perhaps Solenopsis mameti, a much smaller ant that nests mainly in rotten wood in forest shade, would qualify as a competitor. This judgement is based on the generalized feeding habits of similarsized Solenopsis elsewhere in the world, and we have absolutely no direct information on the food of $S$. mameti. At least, the species has not been seen foraging on open paths or tree trunks during the day.

The bright red color and open-trail foraging of $P$. avium suggests reduced predation pressure in the Mauritian native forest habitat, but the possible mimicry with Pristomyrmex bispinosus could on the other hand indicate that predator pressure is appreciable, and in some way answered by protective properties.

In summary, a reasonable hyothesis to explain the atypical "epigaeic characters" of $P$. avium assumes that the ancestral stock reached Mauritius a long time ago from Africa or Asia in a floating log or rotting branch, and established itself in an ant-poor environment that was perhaps also weak in the kinds of predators that attack openforaging ants. Evolution in such an environment, it is argued, led to the reacquisition of characters that had been lost by the parent Proceratium stock during continental specialization to cryptic environments in which arthropod (spider?) eggs had become its main food.

Another hypothesis is that the Mauritian Proceratium retains a sculptural-pilosity pattern primitive for the genus, and that its arthropod egg-feeding proclivities were acquired in an open-foraging situation that elsewhere has since been modified under continental pressures of competition and predation.

In order to throw light on the question, it would be interesting to know exactly what animals the prey eggs on Mauritius belong to, and where and how they are taken by the ants. It may be that we shall never find out, for the mountain forests of Mauritius appear to be teetering on the brink of extinction.

\section{Notes on other species of Proceratium}

Since my summary of Proceratium (Brown, I958: 24I-248), the genus has been found in additional parts of the world. Leston 
( 1971, J. Entomol. (B) 40: i 8-i 19, figs. I, 2, worker, queen) described $P$. boltoni from Ghana; this species appears to be a fourth member of the stictum group, perhaps annectant to the pergandei group.

Borgmeier (1959, An. Acad. Brasil. Ci., 31: 309, worker) described $P$. brasiliense, a close relative of the Central AmericanMexican P. micrommatum, from southeastern Brasil; it is the first representative of the genus from so far south in the New World.

I have found a lone Proceratium queen in rotten wood in wet forest on the lower slopes of Mt. Klabat in northeastern Celebes. The specimen is in the silaceum group and is fairly near P. carinifrons and P. lombokense.

Roy Snelling has published a paper (1967, Contrib. Sci. Los Angeles County Mus., I24: I-IO.) giving further data on $P$. californicum of the West Coast of the United States, plus a key to the New World Proceratium species. The species of the micrommatum group are, however, very close to one another, and I suspect that $P$. convexiceps may eventually be shown to be synonymous with $P$. micrommatum, because the chief character - presence or absence of a triangular median lobe or tooth on the clypeus - involves this small tooth that is very variable in size in the samples from Panama and Mexico. P. micrommatum seems to be widespread in Mexico: Chichicastle, Tabasco (F. Bonet); Pueblo Nuevo, Veracruz (E. O. Wilson); Mesa de Chipinque, near Monterrey, Nuevo Leon (S. and J. Peck) ; Antiguo Morelos, Tamaulipas, litter of palm-thorn forest (S. and J. Peck).

P. normandi Santschi (1929, Bull. Soc. Ent. Belg., 69: 138, worker, queen; type locality La Caille, Algeria and Ain Draham, Tunisia) is a new synonym of $P$. numidicum Santschi (1912, Bull. Soc. Hist. Nat. Afr. Nord, 4: I 72-I 73, figs. I, 2, worker, queen; type locality Ain Draham, Tunisia). In the Santschi Collection, Naturhistorisches Museum, Basel, the types of $P$. numidicum are callow in part, but I could find no other differences between them and the types of $P$. normandi in the same collection.

Proceratium mancum Mann (1922, Proc. U. S. Nat. Mus., 6i (13): 6-7, worker, queen; type locality: Cecilia, Honduras) is a new synonym of $P$. silaceum Roger ( 1863 , Berlin. Entomol. Zeitschr., 7: I72, worker; type locality "Nord-America"). The differences cited by Mann and listed in Snelling's key are all very variable in $P$. silaceum, as is body size. Specimens from the tropical part of the range usually have the petiolar node thinner from front 
to rear, and the posterior face is more or less concave and overhung by the slightly produced posterodorsal nodal border, but a tendency in this direction is seen in some northern specimens, for instance, in a worker from the Ouachita Mts. of southwestern Arkansas, and one from Schooler Lake, Choctaw Co., Oklahoma (W. L. Brown). The geographical gap between Honduras and eastern U. S. is now being filled in to some extent. Already in I9II, W. M. Wheeler had collected specimens in Guatemala (Quirigua and without locality except for the country), and now S. and J. Peck have sent samples from litter berlesates in Veracruz, Mexico: near Cordoba, and in the canyon of the Rio Metlac, near Fortin de las Flores. It should only be a matter of time until we have samples from east Texas and Tamaulipas. This case is paralleled by that of Cryptopone gilva, another ponerine that ranges from the U. S. down through the uplands of Mexico and Central America as far as Panama.

$P$. goliath was taken at Zent, Costa Rica by N. A. Weber, the collection being the first male known for the species, date 17 July 1956. A worker apparently belonging to this species, but a little smaller than the types from Costa Rica, and with a very deep constriction between postpetiole and succeeding segment, comes from Caves Branch, British Honduras (berlesate, S. and J. Peck).

\section{References Cited}

Brown, W. L., JR.

1958. Contributions toward a reclassification of the Formicidae. II. Tribe Ectatommini (Hymenoptera). Bull. Mus. Comp. Zool. Harv., $118: 173-362$.

1971. Characters and synonymies among the genera of ants. Part IV. Some genera of subfamily Myrmicinae (Hymenoptera: Formicidae). Brev. Mus. Comp. Zool., 365:1-5.

DONISTHORPE, H. ST. J. K.

1946. The ants of Mauritius. Ann. Mag. Natur. Hist. (11) 13: 25-35.

1949. A new Camponotus from Madagascar and a small collection of ants from Mauritius. Ann. Mag. Natur. Hist. (12) 2: 271-275.

Kempf, W. W. AND BRown, W. L. JR.

1968. Report on some neotropical ant studies. Pap. Avuls. Zool. S. Paulo, 22: 89-102. 

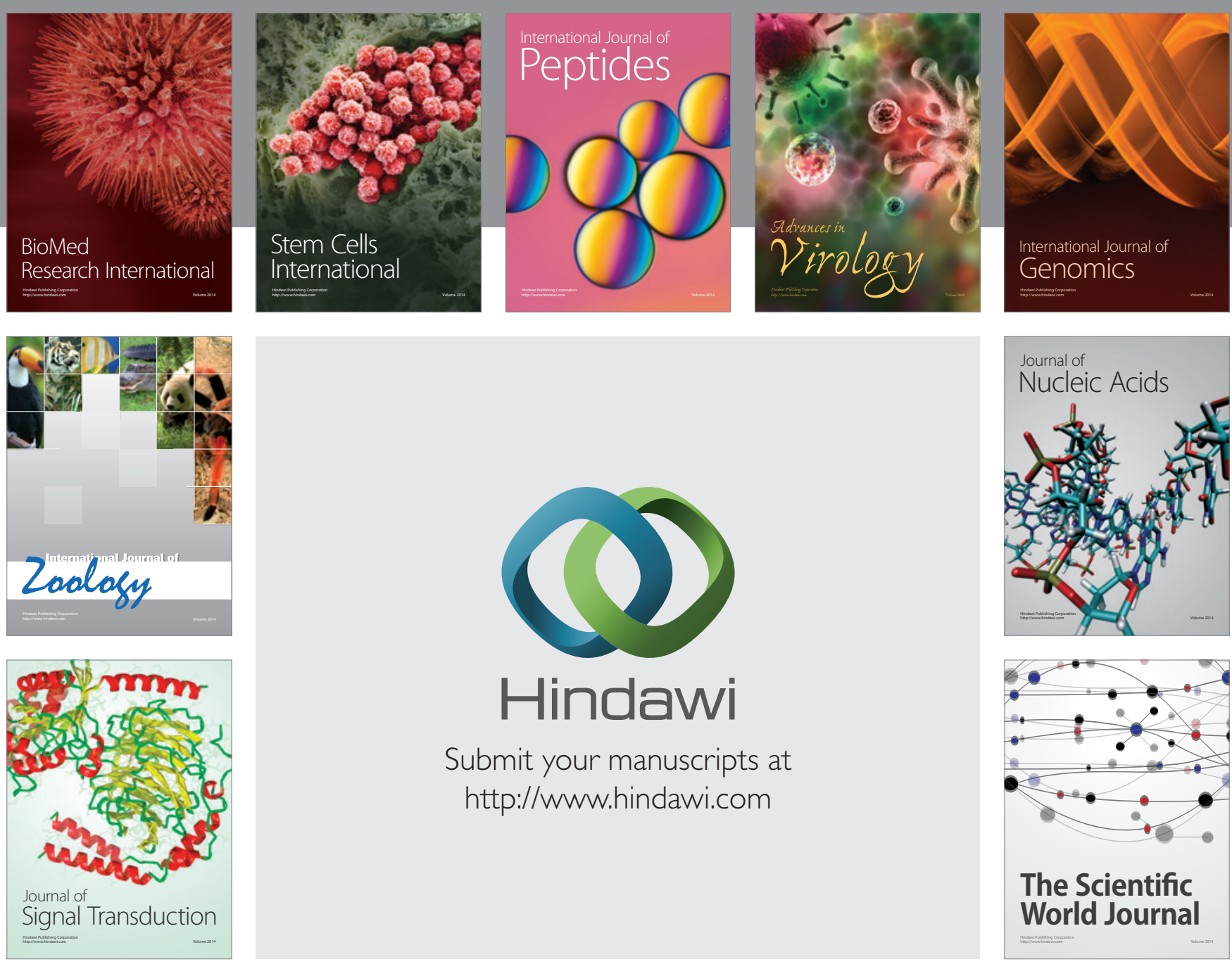

Submit your manuscripts at

http://www.hindawi.com
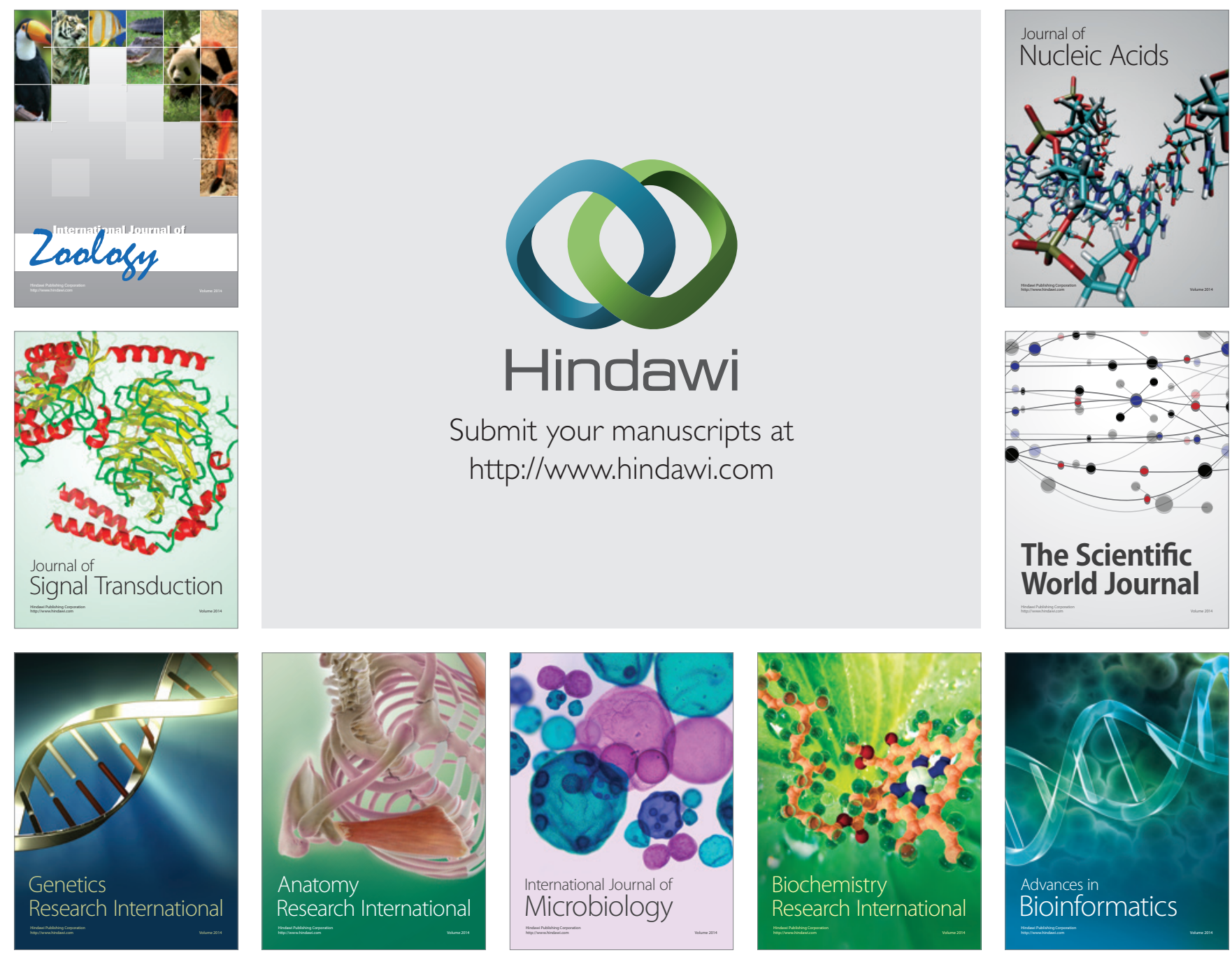

The Scientific World Journal
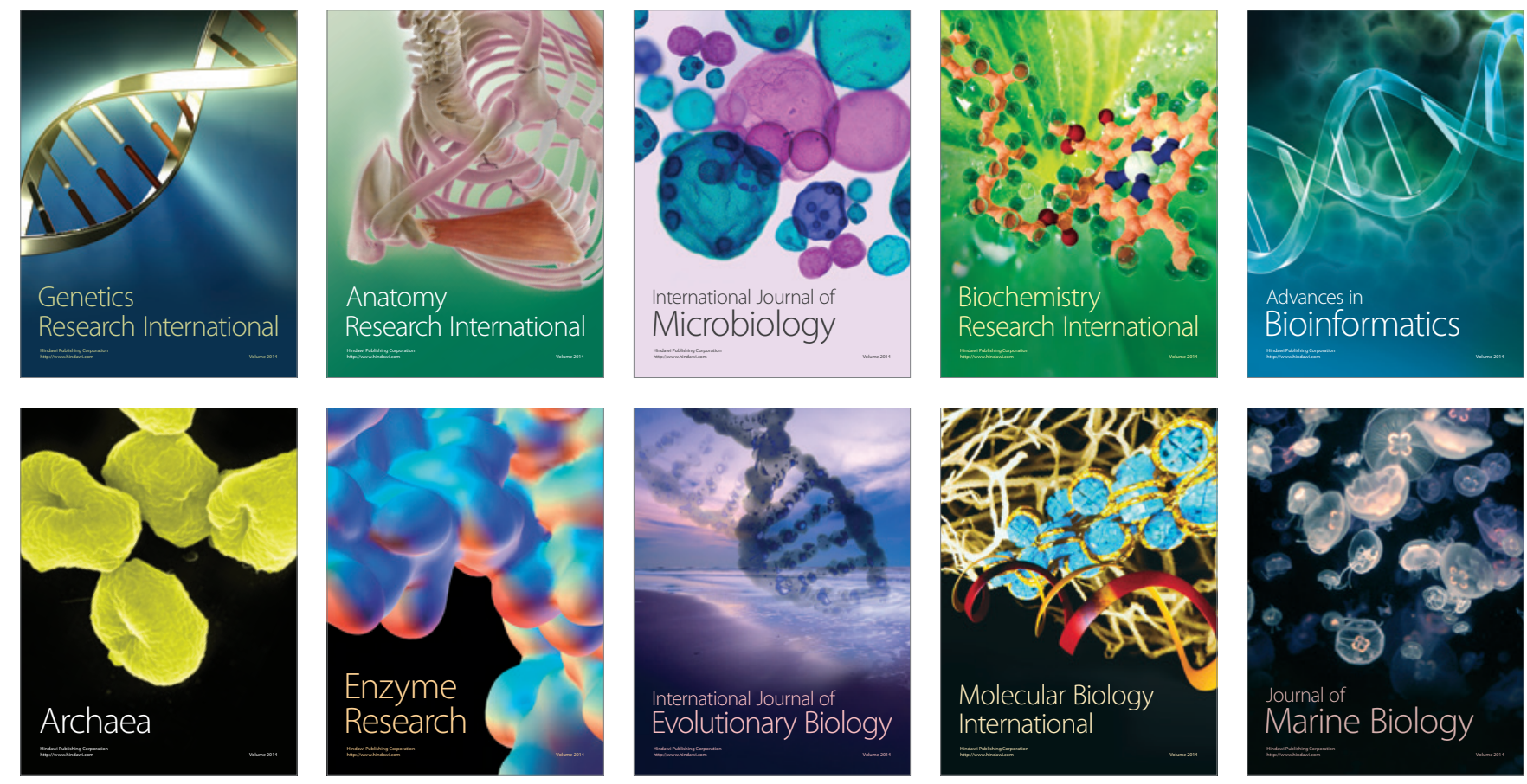